\title{
Anticancer effects of 10-hydroxycamptothecin induce apoptosis of human osteosarcoma through activating caspase-3, p53 and cytochrome $c$ pathways
}

\author{
XIONG MIN*, HAN HENG*, HUA-LONG YU, MAO DAN, CHEN JIE, \\ YUN ZENG, HE NING, ZHI-GANG LIU, ZHI-YONG WANG and WANG LIN \\ Department of Orthopedics Institute, Affiliated Dongfeng Hospital, \\ Hubei University of Medicine, Shiyan, Hubei 442008, P.R. China
}

Received May 3, 2016; Accepted September 1, 2017

DOI: $10.3892 / \mathrm{ol} .2017 .7610$

\begin{abstract}
In order to evaluate the anticancer effect of 10-hydroxycamptothecin (HCPT) in terms of inducing the apoptosis of human osteosarcoma cells, its apoptosis-inducing molecular mechanisms were investigated. In the present study, the anticancer effects of HCPT were revealed to result in suppressed cell viability, increased cytotoxicity, the induction of apoptosis and an augmented apoptotic nucleolus of human osteosarcoma cells. MG-63 cells were cultured with $\operatorname{HCPT}(0,20,40$ and $80 \mathrm{nM})$ for 24 and 48 h. An MTT assay and a lactate dehydrogenase assay were used to analyze the anticancer effect of HCPT on cell viability and cytotoxicity in MG-63 cells. MG-63 cell apoptosis, and caspase- 9 and caspase- 3 activity levels were evaluated using flow cytometry and an ELISA. Western blot analysis was used to detect the protein expression levels of p53, poly (ADP-ribose) polymerase-1 (PARP-1), cytochrome $c$ and B cell lymphoma-2 (Bcl-2) in MG-63 cells. The anticancer effects of HCPT were demonstrated to significantly activate the protein expression of p53, PARP-1 and cytochrome $c$, and suppress Bcl-2 protein expression and promote the activity of caspase- 9 and caspase- 3 in human osteosarcoma cells. In conclusion, the anticancer effects of HCPT appear to induce the apoptosis of human osteosarcoma cells through the activation of the caspase-3, p53 and cytochrome $c$ pathways.
\end{abstract}

Correspondence to: Dr Wang Lin, Department of Orthopedics Institute, Affiliated Dongfeng Hospital, Hubei University of Medicine, 16 Daling Road, Shiyan, Hubei 442008, P.R. China

E-mail: LinWang128@yeah.net

*Contributed equally

Key words: 10-hydroxycamptothecin, osteosarcoma, caspase-3, p53, cytochrome $c$ pathway

\section{Introduction}

Osteosarcoma is a primary malignant bone tumor and originates from osteoblast-like tumor cells or osteoid tumor cells (1). Osteosarcoma often occurs in individuals at 10-25 years of age. The morbidity fastigium is at $\sim 18$ years of age (2). Currently, therapeutic measures include radical limb salvage operations, pre-operative neoadjuvant chemotherapy and post-operative multi-medicine combined chemotherapy (3). For patients whose tumors are restricted to protopathy, the 5-year long-term survival rate is up to $50-70 \%$ (4). Often, once bone tumors have been diagnosed, lung metastatic foci have already formed and patients are unresponsive to chemo-radiotherapy and operations (5). Furthermore, in patients with neoplasm recurrence in later periods, the 5-year long-term survival rate is only $15-20 \%$ (5). Current therapeutic methods include multi-medicine combined chemotherapy, surgical resection and radiotherapy with several courses (4). However, if clinical metastasis is revealed in the first diagnosis or patients are unresponsive to chemo-radiotherapy, particularly for patients with osseous metastasis, prognosis is often negative, and the long-term survival rate is decreased to $15-25 \%$ (3).

The p53 gene is located on chromosome 17p13.1 and is a negative regulatory factor of the cell grow th cycle. Furthermore, it has been demonstrated to be associated with various important biological functions, including the regulation of the cell cycle, DNA repair, cell differentiation and apoptosis (6). The p53 gene is a cancer suppressor gene with a higher mutation rate in malignant tumors (7). Previous research has demonstrated that functional inactivation of the p53 gene serves a crucial function in the occurrence and developmental process of common types of tumor, including lung cancer and breast cancer (8).

In the process of apoptosis, the mitochondrion is the center of apoptosis regulation, with cytochrome $c$ serving a critical function upon its release from the mitochondrion. Once cytochrome $c$ is released into the cytoplasm, it may activate caspases and trigger a cascade reaction, thus resulting in apoptosis. The B cell lymphoma-2 (Bcl-2) protein family regulates the release of cytochrome $c$. The apoptosis induction factor ensures the order of the process of apoptosis. The endoplasmic 
reticulum may improve the sensitivity of the mitochondrion to pro-apoptosis factors through stress, recruitment and activation, so as to allow ease of cytochrome $c$ release from the intermembrane space of the mitochondrion.

In a previous study in 1966, camptothecin was extracted and separated from the plant Camptotheca acuminata (Nyssaceae) in China and was revealed to act on DNA topoisomerase I with good specificity and demonstrates antitumor activity (9). However, due to serious side effects, it is not applied in clinical practice. By studying the pharmacological action mechanism and structure-function relationship of camptothecin, researchers have developed a series of derivatives of camptothecin. 10-hydroxycamptothecin (HCPT; Fig. 1) is a derivative of camptothecin that has medical uses. HCPT may act on DNA topoisomerase I selectively and form stable medical topoisomerase I-DNA complex compounds to disturb the duplication of DNA (10). Such a unique mechanism makes it difficult for HCPT to form cross tolerance with other antineoplastic drugs. Thus, it may form part of a combination treatment with a number of medicines for clinical uses (11). The primary negative effects include myelosuppression and a gastrointestinal reaction. These effects are due to dose-limiting toxicity (12). Currently, HCPT is primarily used in the form of a sodium salt injection. The present study evaluated the anticancer effects of HCPT in inducing the apoptosis of human osteosarcoma cells, and its apoptosis-inducing molecular mechanisms were investigated.

\section{Materials and methods}

Cell culture and hypoxia treatment. Human osteosarcoma MG-63 cells were purchased from the Shanghai Cell Bank of Chinese Academy of Sciences (Shanghai, China) and grown in Dulbecco's modified Eagle medium (Gibco; Thermo Fisher Scientific, Inc., Waltham, MA, USA) supplemented with $10 \%$ fetal bovine serum (Biowest LLC, Kansas City, MO, USA), penicillin $(100 \mathrm{U} / \mathrm{ml})$ and streptomycin $(100 \mu \mathrm{g} / \mathrm{ml})$ at $37^{\circ} \mathrm{C}$ in a humidified atmosphere of $5 \% \mathrm{CO}_{2}$.

Cell viability and cytotoxicity. MG-63 cells were cultured in 96-well plates $\left(\sim 1 \times 10^{4}\right.$ cells/well $)$ and treated with HCPT $(0,20,40$ and $80 \mathrm{nM})$ for 24 and $48 \mathrm{~h}$ at $37^{\circ} \mathrm{C}$. MTT solution $(5 \mathrm{mg} / \mathrm{ml})$ in PBS was added to the cells and incubated for $2 \mathrm{~h}$ at $37^{\circ} \mathrm{C}$. Dimethylsulfoxide was added to the cells prior to incubation for $20 \mathrm{~min}$ at $37^{\circ} \mathrm{C}$. Cell proliferation was measured using an ELISA reader (Beckman Coulter, Inc., Brea, CA, USA) at a wavelength of $540 \mathrm{~nm}$. Lactate dehydrogenase (LDH; $10 \mu \mathrm{l}$ ) was added to the cells using an LDH cytotoxicity assay kit (C0016, Beyotime Institute of Biotechnology, Haimen, China) according to the manufacturer's protocol. Cytotoxicity was measured using the ELISA reader (Beckman Coulter, Inc.) at a wavelength of $500 \mathrm{~nm}$.

Cell apoptosis analysis. MG-63 cells were cultured in 6-well plates $\left(\sim 2 \times 10^{6}\right.$ cells/well) and treated with HCPT $(0,20,40$ and $80 \mathrm{nM}$ ) for $48 \mathrm{~h}$. Cells were then suspended in $500 \mu \mathrm{l}$ binding buffer (BD Pharmingen; BD Biosciences, San Jose, CA, USA) following centrifugation at 2,000 $\mathrm{x}$ g for $5 \mathrm{~min}$ at $4^{\circ} \mathrm{C}$, and were then supplemented with $5 \mu$ l Annexin V (BD Pharmingen; BD Biosciences) and $5 \mu \mathrm{l}$ propidium iodide (BD Pharmingen; BD
Biosciences) for $15 \mathrm{~min}$ in the dark at room temperature. Cell apoptosis was analyzed using a FC 500 MPL flow cytometer (Beckman Coulter, Inc.) and analyzed using FlowJo software (version 7.6.1; FlowJo LLC, Ashland, OR, USA).

Caspase-9 and caspase-3 activity. MG-63 cells were cultured in 96-well plates $\left(\sim 1 \times 10^{4}\right.$ cells/well $)$ and treated with $\operatorname{HCPT}(0,20,40$ and $80 \mathrm{nM})$ for $48 \mathrm{~h}$ at $37^{\circ} \mathrm{C}$. Acetyl (Ac)-Leu-Glu-His-Asp-p-nitroanilide (pNA) substrate for caspase-9 and Ac-Asp-Glu-Val-Asp-pNA substrate for caspase-3 were added to the cells and cultured for $2 \mathrm{~h}$ at $37^{\circ} \mathrm{C}$ (all were purchased from Beyotime Institute of Biotechnology). Caspase-9 and caspase-3 activity was measured using an ELISA reader (Beckman Coulter, Inc.) at a wavelength of $405 \mathrm{~nm}$.

Western blot analysis. For the analysis of apoptosis, MG-63 cells were cultured in 6 -well plates $\left(\sim 2 \times 10^{6}\right.$ cells/well $)$ and treated with $\operatorname{HCPT}(0,20,40$ and $80 \mathrm{nM})$ for $48 \mathrm{~h}$ at $37^{\circ} \mathrm{C}$. MG-63 cells were lysed in radioimmunoprecipitation assay buffer (Beyotime Institute of Biotechnology) containing a phenylmethylsulfonyl fluoride protease inhibitor mixture (PMSF, Beyotime Institute of Biotechnology) at $4{ }^{\circ} \mathrm{C}$ for 15 min. Protein concentration was determined using the Bradford reagent (Bio-Rad Laboratories, Inc., Hercules, CA, USA). Total protein $(50 \mu \mathrm{g})$ was resolved via $10 \%$ SDS-PAGE, and subsequently transferred onto a polyvinylidene fluoride membrane (Merck KGaA, Darmstadt, Germany). The membrane was blocked with $5 \%$ non-fat milk in TBS containing Tween-20 (TBST) for $1 \mathrm{~h}$ at $37^{\circ} \mathrm{C}$ and incubated with primary antibodies against the following antigens: p53 (cat. no. sc-6243, 1:2,000; Santa Cruz Biotechnology, Inc., Dallas, TX, USA), PARP-1 (cat. no. sc-7150, 1:2,000; Santa Cruz Biotechnology, Inc.), cytochrome $c$ (cat. no. sc-7159, 1:2,000; Santa Cruz Biotechnology, Inc.), Bcl-2 (sc-783, 1:2,000; Santa Cruz Biotechnology, Inc.) and $\beta$-actin (cat. no. sc-7210, 1:2,000; Santa Cruz Biotechnology, Inc.) at $4^{\circ} \mathrm{C}$ overnight. The secondary antibody was horseradish peroxidase-conjugated anti-rabbit immunoglobulin G (cat. no. 14708, 1:5,000, Cell Signaling Technology, Inc., Danvers, MA, USA) for $1 \mathrm{~h}$ at $37^{\circ} \mathrm{C}$ subsequent to washing three times for $6 \mathrm{~min}$ each time using TBST and detected using a BeyoECL Plus kit (Beyotime Institute of Biotechnology) according to the manufacturer's protocol and quantified using sodium Image Lab 3.0 (version 3; Bio-Rad Laboratories, Inc.).

Statistical analysis. Results are presented as the mean \pm standard deviation. The statistical analysis was performed using the software SPSS (version 16.0; SPSS, Inc., Chicago, IL, USA). One way analysis of variance and Tukey's post hoc test was used to compare two or more groups of data in order to determine statistical significance. $\mathrm{P}<0.05$ was considered to indicate a statistically significant difference.

\section{Results}

Anticancer effects of HCPT suppress cell viability of human osteosarcoma cells. In order to investigate whether the potential anticancer effects of HCPT suppress the cell growth of human osteosarcoma cells, cell viability was detected using 


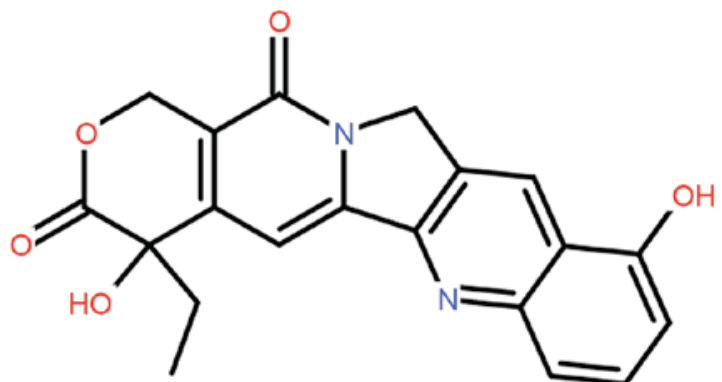

Figure 1. Chemical structure of 10-hydroxycamptothecin.

an MTT assay. Treatment with 0-160 nM HCPT suppressed the cell viability of human osteosarcoma MG-63 cells in a time- and dose-dependent manner (Fig. 2). Treatment with HCPT at $40-160 \mathrm{nM}$ concentrations for $48 \mathrm{~h}$ or $80-160 \mathrm{nM}$ for $24 \mathrm{~h}$ effectively suppressed the cell viability of human osteosarcoma MG-63 cells compared with untreated cells (Fig. 2).

Anticancer effects of HCPT induce the cytotoxicity of human osteosarcoma cells. In addition, the potential anticancer effects of HCPT in terms of increasing the cytotoxicity of human osteosarcoma cells were investigated using an LDH assay. As presented in Fig. 3, treatment with HCPT at 40 and $80 \mathrm{nM}$ concentrations for $48 \mathrm{~h}$ effectively induced the cytotoxicity of human osteosarcoma MG-63 cells.

HCPT induces apoptosis in human osteosarcoma cell. Subsequently, in order to determine the function of the apoptosis rate in the anticancer effects of HCPT on human osteosarcoma cells, flow cytometry was used to analyze the apoptosis rate of human osteosarcoma MG-63 cells. Treatment with 40 and $80 \mathrm{nM} \mathrm{HCPT}$ was demonstrated to effectively induce the apoptosis of human osteosarcoma cells in a dose dependent manner (Fig. 4).

HCPT activates caspase-3 and caspase-9 in human osteosarcoma cells. HCPT activated caspase-3 and caspase-9 in human osteosarcoma cells were investigated. It was revealed that there were effective increases in caspase- 3 and caspase- 9 activity in the human osteosarcoma MG-63 cells treated with 40 and $80 \mathrm{nM} \mathrm{HCPT}$, compared with $0 \mathrm{nM}$ of HCPT (Fig. 5).

HCPT activates the $p 53$ and PARP-1 signaling pathway of human osteosarcoma cells. In order to identify whether HCPT activates the p53 and PARP-1 signaling pathway of human osteosarcoma cells, p53 and PARP-1 protein expression was detected using western blot analysis. As presented in Fig. 6 , HCPT (at 40 and $80 \mathrm{nM}$ concentrations) effectively activated the p53 and PARP-1 protein expression in human osteosarcoma MG-63 cells.

HCPT activates the cytochrome $c$ and Bcl-2 signaling pathway in human osteosarcoma cells. The anticancer effects of HCPT on cytochrome $c$ and Bcl-2 protein expression in human osteosarcoma cells were observed. The group treated with $0 \mathrm{nM}$ HCPT, 40 and $80 \mathrm{nM}$ HCPT suppressed $\mathrm{Bcl}-2$

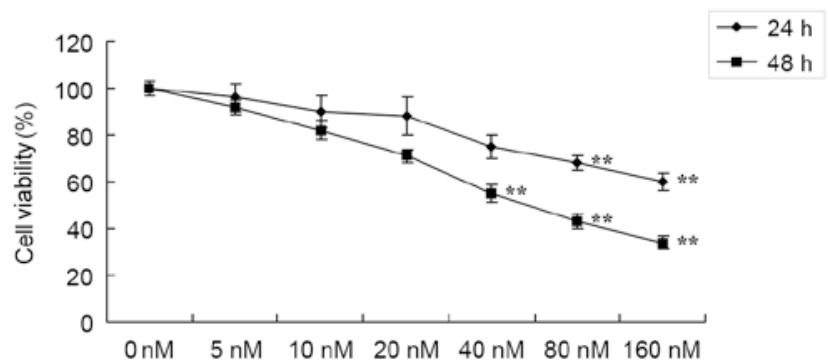

Figure 2. Anticancer effects of 10-hydroxycamptothecin suppress the viability of human osteosarcoma cells. ${ }^{* *} \mathrm{P}<0.01$ vs. $0 \mathrm{nM}$.

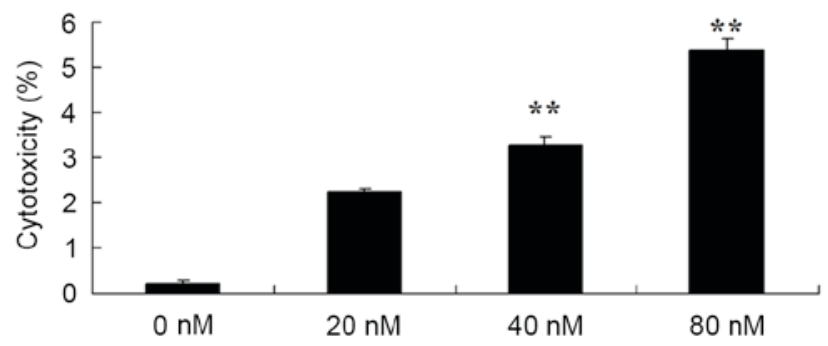

Figure 3. 10-Hydroxycamptothecin induces the cytotoxicity of human osteosarcoma cells. ${ }^{* *} \mathrm{P}<0.01$ vs. $0 \mathrm{nM}$.

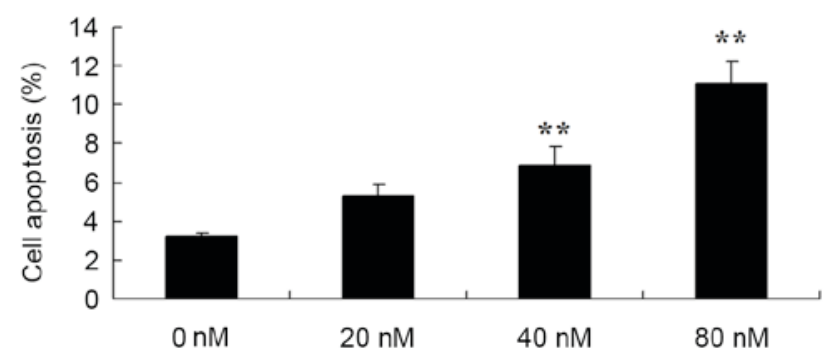

Figure 4. Anticancer effects of 10-hydroxycamptothecin induce apoptosis in human osteosarcoma cells. ${ }^{* *} \mathrm{P}<0.01$ vs. $0 \mathrm{nM}$.

protein levels and increased cytochrome c protein levels in human osteosarcoma MG-63 cells (Fig. 7).

\section{Discussion}

Osteosarcoma is a primary malignant tumor with a higher risk of metastasis. Though it may occur at across all ages, it predominantly occurs in adolescents. It is usually located in long bones, including the distal femur and the proximal tibia (13). Currently, therapy to treat osteosarcoma mainly consists of neoadjuvant chemotherapy combined with surgical resection. A chemotherapy regimen primarily consists of Adriamycin, cis-platinum, ifosfamide and methotrexate (14). The implementation of neoadjuvant chemotherapy improves the prognosis of patients significantly. For patients without metastasis, $\sim 70 \%$ may attain long-term survival (5). Despite this, there are a high number of patients that experience recurrence. The general recurrent tumor foci are long metastatic foci, but local recurrence is not common. In the present study, HCPT was demonstrated to effectively suppress cell viability, and to induce cytotoxicity and the apoptosis of 

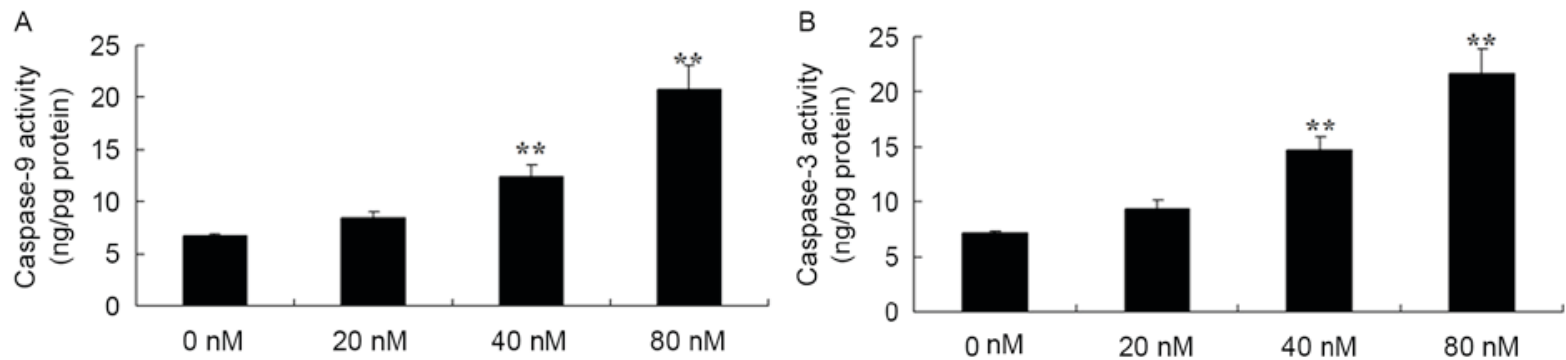

Figure 5. 10-Hydroxycamptothecin activates (A) caspase-3 and (B) caspase-9 in human osteosarcoma cells. ${ }^{* *} \mathrm{P}<0.01$ vs. $0 \mathrm{nM}$.

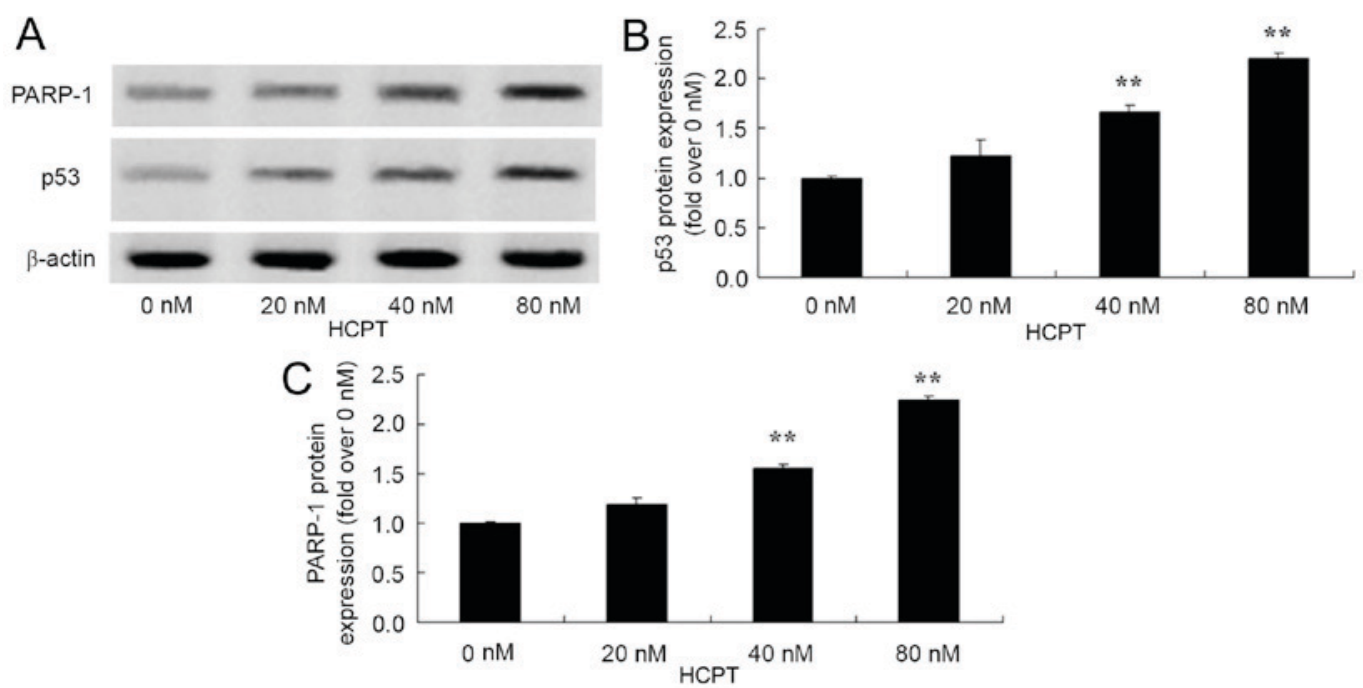

Figure 6. 10-Hydroxycamptothecin activates the p53 and PARP-1 signaling pathway of human osteosarcoma cells. p53 protein expression was analyzed using (A) western blot analysis with (B) quantification of p53 expression and (C) quantification of PARP-1 expression. ${ }^{* *} \mathrm{P}<0.01$ vs. 0 nM. PARP-1, polymerase-1.
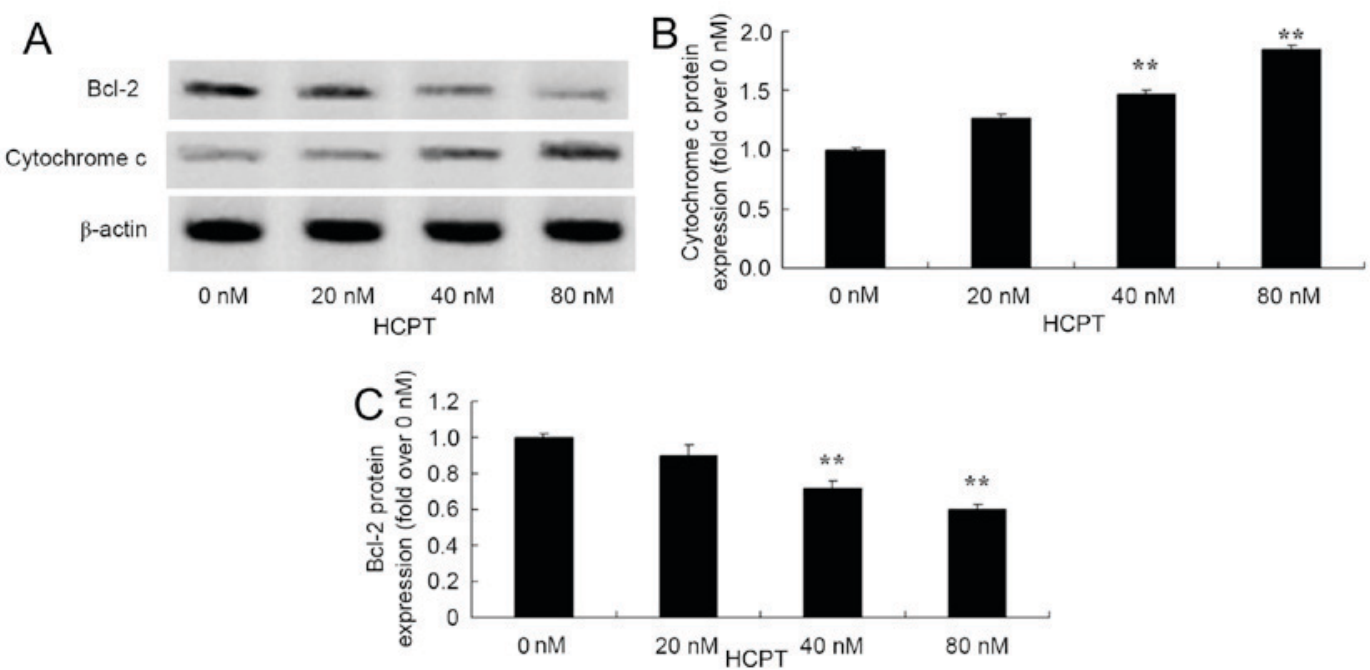

Figure 7. 10-Hydroxycamptothecin activates the cytochrome $c$ and Bcl-2 signaling pathway of human osteosarcoma cells. Cytochrome $c$ and Bcl-2 protein expression was analyzed using (A) western blotting analysis with (B) quantification of cytochrome $c$ expression and (C) quantification of Bcl-2 expression. ${ }^{* *} \mathrm{P}<0.01$ vs. $0 \mu \mathrm{M}$. Bcl-2, B cell lymphoma-2.

human osteosarcoma MG-63 cells. Yang et al (15) suggested that HCPT suppressed the cell growth of human breast cancers, and further studies have demonstrated similar effects in murine melanoma pulmonary cancer (10) and lung cancer (16).
The p53 gene is a tumor suppressor gene and is located in the short arm of the human no. 7 chromosome. This gene codes for the p53 phosphoprotein. The normal function of the p53 phosphoprotein is the regulation of cell proliferation (17). In leukemia, osteosarcoma, lung cancers and colon cancers, 
there may be mutations in and a deficiency of the p53 protein. Previous research has demonstrated that the p53 protein is the most effective natural defense against tumors in the human body $(18,19)$. The present study provides the prospect for a novel protein oncotherapy and protein interaction to identify a novel and effective medical target, as p53 has previously been a hotspot domain of tumor study (8). In the present study, it was revealed that HCPT effectively activated the p53 signaling pathway of human osteosarcoma MG-63 cells. Zhang et al (9) reported that the manner in which HCPT induced apoptosis in HepG2 cells was associated with cell cycle arrest at the G2/M phase through p53 expression.

PARP-1 participates in DNA damage repair and transcription regulation (20). Furthermore, it is regarded as an important regulatory factor of cell survival and cell death, and also participates in the regulation of a number of transcription factors in tumorigenesis and the inflammatory response (20). Currently, increased expression of PARP-1 has been observed in multiple malignant types of tumor, including human osteosarcoma cells (20). As PARP-1 participates in DNA damage repair, the single application of a PARP-1 inhibitor treatment or a DNA damage drug combination may promote apoptosis (21). A previous study has demonstrated that drug inhibition or gene knockout PARP-1 may not only cause the avoidance of tissue damage caused by oxidative stress, but may also improve the prognosis of patients with cancer (22). Additionally, in the present study, HCPT effectively activated the PARP-1 protein expression of human osteosarcoma MG-63 cells. Hu et al (23) observed that HCPT enhanced the apoptosis induced by cancer therapeutic drugs through PARP-1 and caspase-9/3 activation in androgen-independent prostate cancer cells.

Apoptosis, also termed programmed cell death, serves an important function in maintaining the normal physiological equilibrium of the human body and the elimination of old cells (24). Apoptosis is a process by which a gene actively determines the automatic life termination of a cell. Thus it is often termed programmed cell death (25). Apoptosis is a normal process during the individual development of a multicellular organism. It may maintain and resist the disturbance of various outside factors in a stable manner and serves an important function in maturing embryonic development, hematopoiesis and the immune system, in maintaining normal tissues, the organic cell constant and growth balance and also aging (26). In previous years, the focus of studies on apoptosis had shifted from changes in the nucleus to alterations in the mitochondrial respiratory chain. Cytochrome $c$ is a basic component in the respiratory chain and serves an important function in redox and energy metabolism. Furthermore, it has been revealed that cytochrome $c$ is a key substance for the mitochondrion to initiate apoptosis (27). Furthermore, the present study revealed that HCPT effectively activated the cytochrome $c$ signaling pathway of human osteosarcoma MG-63 cells. Yuan et al (12) indicated that HCPT induces apoptosis through the p53, cytochrome $c$ and caspase-3 pathways of human neuroblastoma SMS-KCNR cells.

Under normal circumstances, cytochrome $c$ exists in the cavity between the inner and outer mitochondrial membranes (28). The signal stimulation of apoptosis causes the release of cytochrome $c$ from the mitochondria to the cytoplasm. Once cytochrome $c$ is released, it may cause one of two consequences. One is that it may combine with apoptotic peptidase activating factor-1. Under the mediation of adenosine triphosphate/deoxyadenosine triphosphate, the caspase-9 precursor is split into activated caspase-9 (28). The activated caspase-9 activates caspase-3 and results in apoptosis (29). As cytochrome $c$ is released into the cytoplasm, intracellular cytochrome $c$ is reduced or absent, and therefore may result in the interruption of the respiratory chain electron transfer chain and necrocytosis (30). The release of cytochrome $c$ is the result of an increase in the permeability of the mitochondrial outer membrane (31). Bcl-2 proteins are primarily concentrated in the mitochondrial outer membrane, and prevent it from releasing cytochrome $c$, which inactivates the caspase in the cytoplasm, and causes apoptosis to be blocked. Caspase- 3 is one of the most important executors of apoptosis (31). Activated caspase-3 may degrade Bcl-2 protein and prevent it from carrying out its anti-apoptotic effects. Once caspase-3 is activated, the occurrence of apoptosis is irreversible (29). In the present study, it was revealed that HCPT effectively promoted caspase-3/9 activities and inhibited the protein expression of Bcl-2 in human osteosarcoma MG-63 cells. Yuan et al (12) had previously indicated that HCPT induces apoptosis through the p53, cytochrome $c$ and caspase-3 pathways of human neuroblastoma SMS-KCNR cells.

In conclusion, the results of the present study demonstrate that HCPT effectively suppresses cell viability, induces cytotoxicity and the apoptosis of human osteosarcoma MG-63 cells, through the use of modulated caspase-3, p53 and cytochrome $c$ pathways. The data of the present study indicated that HCPT may be a prognostic drug and a therapeutic target for human osteosarcoma.

\section{References}

1. Kurzman ID, MacEwen EG, Rosenthal RC, Fox LE, Keller ET, Helfand SC, Vail DM, Dubielzig RR, Madewell BR, Rodriguez CO Jr, et al: Adjuvant therapy for osteosarcoma in dogs: Results of randomized clinical trials using combined liposome-encapsulated muramyl tripeptide and cisplatin. Clin Cancer Res 1: 1595-1601, 1995.

2. Meyers PA, Schwartz CL, Krailo M, Kleinerman ES, Betcher D, Bernstein ML, Conrad E, Ferguson W, Gebhardt M, Goorin AM, et al: Osteosarcoma: A randomized, prospective trial of the addition of ifosfamide and/or muramyl tripeptide to cisplatin, doxorubicin, and high-dose methotrexate. J Clin Oncol 23: 2004-2011, 2005.

3. Fan TM, Charney SC, de Lorimier LP, Garrett LD, Griffon DJ, Gordon-Evans WJ and Wypij JM: Double-blind placebo-controlled trial of adjuvant pamidronate with palliative radiotherapy and intravenous doxorubicin for canine appendicular osteosarcoma bone pain. J Vet Intern Med 23: 152-160, 2009.

4. Goldsby RE, Fan TM, Villaluna D, Wagner LM, Isakoff MS, Meyer J, Randall RL, Lee S, Kim G, Bernstein M, et al: Feasibility and dose discovery analysis of zoledronic acid with concurrent chemotherapy in the treatment of newly diagnosed metastatic osteosarcoma: A report from the Children's Oncology Group. Eur J Cancer 49: 2384-2391, 2013.

5. Zhao J, Xu H, He M, Wang Z and Wu Y: Rho GTPase-activating protein 35 rs 1052667 polymorphism and osteosarcoma risk and prognosis. Biomed Res Int 2014: 396947, 2014.

6. Tóth C, Meinrath J, Herpel E, Derix J, Fries J, Buettner R, Schirmacher $\mathrm{P}$ and Heikaus S: Expression of the apoptosis repressor with caspase recruitment domain (ARC) in liver metastasis of colorectal cancer and its correlation with DNA mismatch repair proteins and p53. J Cancer Res Clin Oncol 142: 927-935, 2016.

7. Deorukhkar A, Ahuja N, Mercado AL, Diagaradjane P, Raju U, Patel N, Mohindra P, Diep N, Guha S and Krishnan S: Zerumbone increases oxidative stress in a thiol-dependent ROS-independent manner to increase DNA damage and sensitize colorectal cancer cells to radiation. Cancer Med 4: 278-292, 2015. 
8. Véquaud E, Desplanques G, Jézéquel P, Juin P and Barillé-Nion S: Survivin contributes to DNA repair by homologous recombination in breast cancer cells. Breast Cancer Res Treat 155: 53-63, 2016.

9. Zhang XW, Jiang JF and Xu B: Differentiation-inducing action of 10-hydroxycamptothecin on human hepatoma Hep G2 cells Acta Pharmacol Sin 21: 364-368, 2000.

10. Hu W, Zhang C, Fang Y and Lou C: Anticancer properties of 10-hydroxycamptothecin in a murine melanoma pulmonary metastasis model in vitro and in vivo. Toxicol In Vitro 25: 513-520, 2011

11. Wei W, Shi SJ, Liu J, Sun X, Ren K, Zhao D, Zhang XN, Zhang ZR and Gong T: Lipid nanoparticles loaded with 10-hydroxycamptothecin-phospholipid complex developed for the treatment of hepatoma in clinical application. J Drug Target 18: 557-566, 2010.

12. Yuan ZF, Tang YM, Xu XJ, Li SS and Zhang JY: 10 -Hydroxycamptothecin induces apoptosis in human neuroblastoma SMS-KCNR cells through p53, cy tochrome c and caspase 3 pathways. Neoplasma 63: 72-79, 2016

13. Gallegos-Castorena S, Martínez-Avalos A, Mohar-Betancourt A Guerrero-Avendaño G, Zapata-Tarrés M and Medina-Sansón A: Toxicity prevention with amifostine in pediatric osteosarcoma patients treated with cisplatin and doxorubicin. Pediatr Hemato Oncol 24: 403-408, 2007.

14. Navid F, Santana VM, Neel M, McCarville MB, Shulkin BL, Wu J, Billups CA, Mao S, Daryani VM, Stewart CF, et al: A phase II trial evaluating the feasibility of adding bevacizumab to standard osteosarcoma therapy. Int J Cancer 141: 1469-1477, 2017.

15. Yang Z, Luo X, Zhang X, Liu J and Jiang Q: Targeted delivery of 10-hydroxycamptothecin to human breast cancers by cyclic RGD-modified lipid-polymer hybrid nanoparticles. Biomed Mater 8: 025012, 2013.

16. Zhang X, Gan Y, Gan L, Nie S and Pan W: PEGylated nanostructured lipid carriers loaded with 10-hydroxycamptothecin: An efficient carrier with enhanced anti-tumour effects against lung cancer. J Pharm Pharmacol 60: 1077-1087, 2008.

17. Carvalho S, Vitor AC, Sridhara SC, Martins FB, Raposo AC, Desterro JM, Ferreira J and de Almeida SF: SETD2 is required for DNA double-strand break repair and activation of the p53-mediated checkpoint. Elife 3: e02482, 2014.

18. Dutta S, Warshall C, Bandyopadhyay C, Dutta D and Chandran B: Interactions between exosomes from breast cancer cells and primary mammary epithelial cells leads to generation of reactive oxygen species which induce DNA damage response, stabilization of 553 and autophagy in epithelial cells. PLoS One 9: e97580, 2014.

19. Simone CB II, John-Aryankalayil M, Palayoor ST, Makinde AY, Cerna D, Falduto MT, Magnuson SR and Coleman CN: mRNA expression profiles for prostate cancer following fractionated irradiation are influenced by p53 status. Transl Oncol 6: 573-585, 2013.
20. Uchiumi F, Watanabe T, Ohta R, Abe H and Tanuma S: PARP1 gene expression is downregulated by knockdown of PARG gene. Oncol Rep 29: 1683-1688, 2013.

21. Halder AK, Saha A, Saha KD and Jha T: Stepwise development of structure-activity relationship of diverse PARP-1 inhibitors through comparative and validated in silico modeling techniques and molecular dynamics simulation. J Biomol Struct Dyn 33: 1756-1779, 2015.

22. Dawicki-McKenna JM, Langelier MF, DeNizio JE, Riccio AA, Cao CD, Karch KR, McCauley M, Steffen JD, Black BE and Pascal JM: PARP-1 activation requires local unfolding of an autoinhibitory domain. Mol Cell 60: 755-768, 2015.

23. Hu H, Jiang C, Ip C, Rustum YM and Lü J: Methylseleninic acid potentiates apoptosis induced by chemotherapeutic drugs in androgen-independent prostate cancer cells. Clin Cancer Res 11: 2379-2388, 2005.

24. Zhou J, Wu S, Chen Y, Zhao J, Zhang K, Wang J and Chen S: microRNA-143 is associated with the survival of ALDH1+CD133+ osteosarcoma cells and the chemoresistance of osteosarcoma. Exp Biol Med (Maywood) 240: 867-875, 2015.

25. Ye Z, Jingzhong L, Yangbo L, Lei C and Jiandong Y: Propofol inhibits proliferation and invasion of osteosarcoma cells by regulation of microRNA-143 expression. Oncol Res 21: 201-207, 2013.

26. Kwon HY, Kim KS, An HK, Moon HI, Kim HJ and Lee YC: Triptolide induces apoptosis through extrinsic and intrinsic pathways in human osteosarcoma U2OS cells. Indian J Biochem Biophys 50: 485-491, 2013

27. Li J, Zhang F and Wang S: A polysaccharide from pomegranate peels induces the apoptosis of human osteosarcoma cells via the mitochondrial apoptotic pathway. Tumour Biol 35: 7475-7482, 2014.

28. Sun Z, Huang K, Fu X, Zhou Z, Cui Y and Li H: A chemically sulfated polysaccharide derived from Ganoderma lucidum induces mitochondrial-mediated apoptosis in human osteosarcoma MG63 cells. Tumour Biol 35: 9919-9926, 2014.

29. Chipoy C, Brounais B, Trichet V, Battaglia S, Berreur M, Oliver L, Juin P, Rédini F, Heymann D and Blanchard F: Sensitization of osteosarcoma cells to apoptosis by oncostatin M depends on STAT5 and p53. Oncogene 26: 6653-6664, 2007.

30. Roepke M, Diestel A, Bajbouj K, Walluscheck D, Schonfeld P, Roessner A, Schneider-Stock R and Gali-Muhtasib H: Lack of p53 augments thymoquinone-induced apoptosis and caspase activation in human osteosarcoma cells. Cancer Biol Ther 6 : 160-169, 2007.

31. Cao X, Bennett RL and May WS: c-Myc and caspase-2 are involved in activating Bax during cytotoxic drug-induced apoptosis. J Biol Chem 283: 14490-14496, 2008. 